\title{
Agrobacterium-Mediated Transformation of Mexican Lime (Citrus aurantifolia Swingle) Using Optimized Systems for Epicotyls and Cotyledons
}

\author{
Maria Luiza P. de Oliveira1 ${ }^{*}$, Gloria Moore ${ }^{2}$, James G. Thomson ${ }^{3}$, Ed Stover ${ }^{1}$ \\ ${ }^{1}$ USDA-ARS Subtropical Insects and Horticulture Research Unit, Fort Pierce, USA \\ ${ }^{2}$ Horticultural Science Department, Institute of Food and Agricultural Science, University of Florida, Gainesville, \\ USA \\ ${ }^{3}$ USDA-ARS Crop Improvement and Utilization, Albany, USA \\ Email: "Maria.Oliveira@ars.usda.gov
}

Received 29 September 2015; accepted 13 November 2015; published 16 November 2015

Copyright (C) 2015 by authors and Scientific Research Publishing Inc.

This work is licensed under the Creative Commons Attribution International License (CC BY). http://creativecommons.org/licenses/by/4.0/

(c) (i) Open Access

\section{Abstract}

Transgenic Mexican lime (Citrus aurantifolia Swingle) was produced through two explant sources, each using systems previously optimized for each source. One used epicotyls segments, which was the predominant explant for transgenic Citrus production following co-cultivation with Agrobacterium, and has a well-established protocol. The other procedure used embryo cotyledons from mature seeds, which was developed in our lab as an alternative for stable Citrus transformation. Cotyledon transformation and regeneration protocols were optimized by comparing variables in culture medium composition on shoot regeneration and four parameters in transient transformation. The optimized protocols were compared, and frequency of regeneration, frequency of transgenic plant-recovery and stable transformation efficiency indicated the superiority of the cotyledon protocol for Agrobacterium-mediated genetic transformation in Mexican lime. The tissue choice resulted in marked improvement in shoot regeneration $(14.1 \%$ of explants producing shoots in epicotyls; $55.8 \%$ in cotyledons), stable transformation frequency (11.4\% of epicotyls explants; $40.2 \%$ in cotyledons), and frequency of transgenic plant-recovery (37.9\% in epicotyl explants; $92.6 \%$ in cotyledons). Thus, easy availability of explants using embryo cotyledons from mature seeds, technical simplicity, shortening of transformation time-course, and higher transformation and regeneration frequencies makes this new system an attractive alternative over the previously published Citrus transformation protocols. In the course of this project, we generated Mexican lime with a Recombinase Mediated Exchange Cassette landing pad, which was designed for stacking transgenes.

${ }^{*}$ Corresponding author.

How to cite this paper: de Oliveira, M.L.P., Moore, G., Thomson, J.G. and Stover, E. (2015) Agrobacterium-Mediated Transformation of Mexican Lime (Citrus aurantifolia Swingle) Using Optimized Systems for Epicotyls and Cotyledons. Advances in Bioscience and Biotechnology, 6, 657-668. http://dx.doi.org/10.4236/abb.2015.611069 
Keywords

Agrobacterium tumefaciens, Embryo Cotyledons, Epicotyls Segments,
Recombinase Mediated Exchange Cassette, Tissue Culture

\section{Introduction}

The genetic transformation of Citrus has been widely studied as a tool to generate transgenic plants with enhanced tolerance of biotic [1]-[4] and/or abiotic stresses [5]. These protocols have relied on somatic embryogenesis from nucellar calli [6] or from protoplast-derived cultures [7], or more commonly, shoot organogenesis from epicotyl or internodal stem segments [8]-[11]. However, most of these A. tumefaciens-based systems have shown low transformation efficiencies, and/or transgenic plant-recovery.

Physiological state, ontogeny of explants and the explant-source position on mother plants greatly affects in vitro development. Different explant sources have different growth potential due to differences in age, and endogenous metabolic status [12] [13]. Likewise, Barcelo-Munoz et al. 1999 [14] reported that the choice of an appropriate explant is critical for success in morphogenesis and the ability of various types to respond for regeneration on their inheritance capabilities. Some efforts have been undertaken to explore other explants to develop an improved transformation system, with high capacity for regeneration and a shorter transformation time. Gene transfer into readily available tissue explants and regeneration without substantial in vitro culture are desirable characteristics to consider in evaluating alternative techniques for genetic transformation [15]. The resources required to maintain a continuous supply of explants at the correct developmental stage for transformation to be substantial.

Previous reports using epicotyls segments from Mexican lime have shown low affinity for Agrobacterium tumefaciens infection which results in low transformation efficiency [16] [17]. Therefore we decided to explore the use of cotyledons as an explant source. In the present study, we examined the timing and frequency of transformation between the conventional protocol, using epicotyls as explants, and an alternative optimized protocol for Agrobacterium-mediated transformation in Mexican lime. The alternative protocol using cotyledons from mature seeds provided an improvement in regeneration capacity, longer shoots and robust rooting, with a very simple transformation procedure, reducing the timing for transgenic Mexican lime plant-recovery. Application of this procedure may also accelerate the efficient recovery of other Citrus recalcitrant genotypes from in vitro transformation.

\section{Materials and Methods}

\subsection{Plant Material and Explants Preparations}

Seeds of Mexican lime were extracted from mature fruits and stored in a refrigerator at $4^{\circ} \mathrm{C}$ until used. They were surface sterilized under aseptic conditions for $1 \mathrm{~min}$ in $70 \%(\mathrm{v} / \mathrm{v})$ ethanol, and further immersed in a solution containing 2.5\% (v/v) sodium hypochlorite (Clorox, USA) and $0.02 \%(\mathrm{v} / \mathrm{v})$ tween 20, then rinsed three times with sterile distilled water. For seedling epicotyl explant transformation, sterilized seeds were placed onto Citrus seed germination medium (MS medium solidified with $2.4 \mathrm{~g} \cdot \mathrm{L}^{-1}$ gelrite) in tall Magenta vessels, and incubated at $27^{\circ} \mathrm{C}$ for 30 days in the darkness, followed by 7 - 10 days on a 16/8h light/dark cycle. The light green seedling epicotyls were aseptically cut for co-culture with Agrobacterium. For cotyledon isolation, the sterilized seeds were dried overnight, and the two seed coats were peeled off aseptically, the embryonic axes were aseptically removed, and their cotyledons were used directly as explants.

\subsection{Adventitious Shoot Induction Medium for Cotyledon Explants}

For regeneration experiments from cotyledons, explants were placed on MS salts with $30 \mathrm{~g} \cdot \mathrm{L}^{-1}$ sucrose, and supplemented with different combinations of 6-benzylaminopurine (BAP), $\alpha$-naphthalene acetic acid (NAA), Indole acetic acid (IAA) and 6-furfuryl-aminopurine (Kin), using a factorial design. The medium was , brought to $\mathrm{pH} 5.7 \pm 0.1$ prior to the addition of agar, solidified with $6 \mathrm{~g} \cdot \mathrm{L}^{-1}$ agar (Sigma), and autoclaved at $121^{\circ} \mathrm{C}$ for 25 min. The cotyledons were placed exterior surface (previously in contact with seed coat) down in contact with the 
medium. For each treatment at least 50 explants (5 plates) were cultured. Cultures were initially incubated in darkness at $27^{\circ} \mathrm{C} \pm 1^{\circ} \mathrm{C}$ for 3 weeks and then transferred to a 16/8-h (light/dark) photoperiod for 3 weeks with 36 $\mu \mathrm{mol} \cdot \mathrm{m}^{-2} \cdot \mathrm{s}^{-1}$ radiation provided by fluorescent tubes. All treatments were repeated twice.

\subsection{Sensitivity Test of "Mexican Lime" Cotyledons to Kanamycin}

Prior to transformation, an effective concentration of kanamycin was determined for selection of transformants by culturing non-transgenic cotyledon explants on regeneration medium (MS medium supplemented with 2 $\mathrm{mg} \cdot \mathrm{L}^{-1}$ BAP, $1 \mathrm{mg} \cdot \mathrm{L}^{-1}$ Kin, $1 \mathrm{mg} \cdot \mathrm{L}^{-1} \mathrm{NAA}, 3 \%$ sucrose and $0.6 \%$ agar) containing different concentrations of kanamycin $\left(0,15,20,25,30,40,50,60 \mathrm{mg} \cdot \mathrm{L}^{-1}\right)$, and incubated in darkness for 3 weeks followed by $16 \mathrm{~h}$ photoperiod with fluorescent light ( $36 \mu \mathrm{mol} \cdot \mathrm{m}^{-2} \cdot \mathrm{s}^{-1}$ light radiation) at $27^{\circ} \mathrm{C} \pm 1^{\circ} \mathrm{C}$ for 3 weeks. Each treatment had 5 petri dishes with 5 explants. Frequency of explants forming shoots and the number of shoots per explants were recorded. All experiments were repeated twice.

\subsection{Optimized Conditions Evaluated for Transient Agrobacterium Transformation of Cotyledon Explants}

The transformation parameters were optimized for cotyledon explants using the bacterial strain EHA 105 harboring the pCTAGDV-KCN3 binary vector [18]. Parameters were tested, one at a time, in a sequential order. The optimized conditions determined in earlier experiments were used in subsequent experiments. The following four parameters (and treatments) were tested in the order stated: 1) Agro infiltration method (use of vacuum chamber during inoculation and/or dipping); 2) density of bacterial culture; 3) duration of co-cultivation period; and 4) concentration of acetosyringone transformation enhancer.

For testing the first parameter, the cotyledon explants were placed in $50 \mathrm{ml}$ Falcon tubes with $15 \mathrm{ml}$ of Agrobacterium suspension $\left(\mathrm{OD}_{600}=0.5\right)$ and were subject to different vacuum durations $(5,10,15,20$ and 25 min). After vacuum inoculation the explants were maintained in Agrobacterium solution for an additional 10 min. These treatments were compared with only immersion of the explants into Agrobacterium inoculum ("dipping”). To compare the effect of Agrobacterium concentration (0.25, 0.50, 0.75 and $1.0 \mathrm{OD}_{600}$ ), explants were placed in $50 \mathrm{ml}$ Falcon tubes with $10 \mathrm{ml}$ Agrobacterium suspension and kept under vacuum for 15 minutes, followed by an additional $10 \mathrm{~min}$ in Agrobacterium inoculum. The effects of co-culture period and the presence of acetosyringone (AS) during co-cultivation period were evaluated, and the cotyledons inoculated with Agrobacterium were placed on co-cultivation medium for $0,1,2,3$ or 4 days, and the best co-culture period was selected to analyze the effect of transformation enhancer acetosyringone during the co-culture (concentrations at 0, 50, 100 or $150 \mu \mathrm{M}$ ). All parameters were evaluated using transient DsRed expression as described below.

\subsection{DsRed Expression Assay}

The expression of DsRed was observed in cotyledon explants under a fluorescent microscope (Olympus BX3) at 10x magnification and the appropriate filter for detection of the red fluorescence of the DsRed protein, which has an excitation maximum at $545 \mathrm{~nm}$ and emission maximum at $600 \mathrm{~nm}$. Comparisons of the transient DsRed expression levels were made by counting DsRed expressing explants 10 days after co-cultivation. After Agrobacterium inoculation, explants were blotted on filter paper, transferred to co-culture medium for 3 days, which was then transferred to the selection medium for an additional 10 days. Analysis for each parameter used twenty five cotyledon explants and was repeated thrice.

\subsection{Stable Transformation and Selection of Transgenic Plants}

Agrobacterium tumefaciens strain EHA 105/pCTAGDV-KCN3, described in De Oliveira et al. 2015 [18], was cultured overnight in an orbital shaker at $28^{\circ} \mathrm{C}$ in $50 \mathrm{ml}$ of YEP medium containing $100 \mathrm{mg} \cdot \mathrm{L}^{-1}$ kanamycin. Bacterial cells were harvested by centrifugation at $3500 \mathrm{rpm}$ for $5 \mathrm{~min}$, resuspended to the designated $\mathrm{OD}_{600}$ in liquid MS basal medium containing $100 \mu \mathrm{M}$ acetosyringone for explant inoculation. The $A$. tumefaciens suspension described above was used for epicotyl and cotyledon transformation.

Figure 1 outlines the procedure for epicotyl and cotyledon explant transformation in Mexican lime. An epicotyl transformation protocol was previously described by De Oliveira et al., 2015 [18]. The optimized protocol was established for Agrobacterium-mediated transformation of Citrus using cotyledons as described below. The 


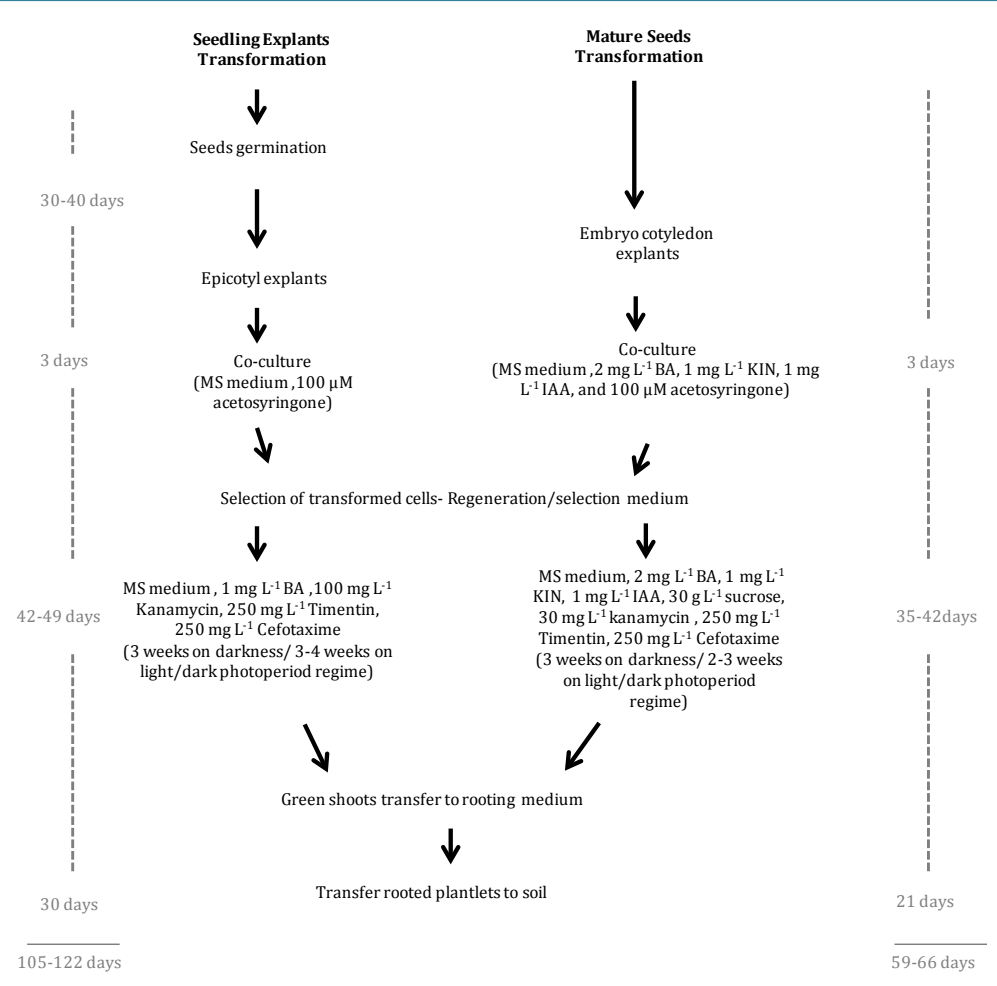

Figure 1. Outline of A. tumefaciens-mediated transformation protocols for epicotyls and cotyledon explants for Mexican lime.

cotyledons were isolated, placed into $50 \mathrm{ml}$ Falcon tubes containing $10 \mathrm{ml}$ Agrobacterium suspension $\left(\mathrm{OD}_{600}=\right.$ 0.50) and exposed to vacuum infiltration for $15 \mathrm{~min}$ (vacuum pump at $0.25 \mathrm{MPa}=75 \mathrm{in}$. of $\mathrm{Hg}$ ). Following incubation, explants were blotted dry on sterile filter paper and placed exterior side down on semi-solid co-cultivation medium (MS basal medium containing $2 \mathrm{mg} \cdot \mathrm{L}^{-1} \mathrm{BAP}, 1 \mathrm{mg} \cdot \mathrm{L}^{-1} \mathrm{Kin}$ and $1 \mathrm{mg} \cdot \mathrm{L}^{-1} \mathrm{IAA}, 100 \mu \mathrm{M}$ acetosyringone and $30 \mathrm{~g} \cdot \mathrm{L}^{-1}$ sucrose). Co-cultivation was conducted in the dark at $27^{\circ} \mathrm{C} \pm 1^{\circ} \mathrm{C}$, for 3 days. The explants were then transferred to selection medium (MS medium containing $2 \mathrm{mg} \cdot \mathrm{L}^{-1} \mathrm{BAP}, 1 \mathrm{mg} \cdot \mathrm{L}^{-1} \mathrm{Kin}, 1$ $\mathrm{mg} \cdot \mathrm{L}^{-1} \mathrm{IAA}, 30 \mathrm{mg} \cdot \mathrm{L}^{-1}$ sucrose, $250 \mathrm{mg} \cdot \mathrm{L}^{-1}$ timentin, $250 \mathrm{mg} \cdot \mathrm{L}^{-1}$ cefotaxime, and $\left.30 \mathrm{mg} \cdot \mathrm{L}^{-1} \mathrm{kanamycin}\right)$ and maintained in darkness for 3 weeks, followed by incubation under a $16 / 8 \mathrm{~h} \mathrm{light/dark} \mathrm{photoperiod} \mathrm{regime} \mathrm{at} 27^{\circ} \mathrm{C}$ $\pm 1^{\circ} \mathrm{C}$, for an additional 3 weeks.

\subsection{Molecular Analysis}

Genomic DNA was isolated from leaves of transgenic and non-transgenic plants as previously described by Štorchová et al. (2000) [19]. For each sample of DNA, 100 ng of genomic DNA in $25 \mu L$ volume was used per PCR reaction. CodAORF70F60 and CodAORF1137R60 primers 5' CAAGACCCTTCCTCTATATAAG-3' and 5'-CGAGTTCATAGAGATAACCTTC-3', were used to detect the negative selectable marker sequence. The expected fragment size of the amplified DNA segment is $1067 \mathrm{bp}$. As a control, DNA from non-transgenic cv. Carrizo was included in each PCR screening. PCR positive transgenic plants were subsequently confirmed by Southern Blot. Ten micrograms of genomic DNA of non-transgenic (NT) and transgenic plants were digested with EcoRI for $6 \mathrm{~h}$ at $37^{\circ} \mathrm{C}$ and separated by electrophoresis on a $0.8 \%(\mathrm{w} / \mathrm{v})$ agarose gel. The DNA was then transferred to a Hybond-N membrane (Amersham) and hybridized with the ${ }^{32} \mathrm{P}$-labelled codA sequence (Produced by Promega TaqTM polymerase using primers CodAORF70F60 5' CAAGACCCTTCCTCTATAT AAG-3' and CodAORF1137R60 5'-CGAGTTCATAGAGATAACCTTC-3') as described by De Oliveira et al. (2015) [18].

\subsection{Statistical Analysis}

All data were analyzed by analysis of variance (ANOVA) and Tukey’s multiple comparison tests at 5\% proba- 
bility for all the variables studied.

\section{Results and Discussion}

\subsection{Comparison of PGR Composition on Adventitious Shoot Regeneration}

Most of the published protocols for Agrobacterium-mediated transformation in Citrus have used epicotyls as target cells for incorporation of the T-DNA [20]. Here, the cotyledons were extracted from mature seeds and conditions for regeneration and Agrobacterium transformation were optimized.

In preliminary studies, the cotyledons from seeds of Mexican lime were cultured on different media formulations containing different concentrations of BAP, Kin, NAA, and IAA (Figure 2). The results indicated that the frequency of explants with shoots and subsequent number of the shoots per explants were influenced by the type of plant growth regulator as well as concentration and combination of cytokinin or auxin. In the present study, the two cytokinins, BAP and Kin exerted a synergistic effect on the proportion of cotyledons producing shoots and the number of shoots per explants. Both parameters were higher for the cytokinin combination than for either cytokinin alone. The number of cotyledon segments forming shoots and the number of shoots per cotyledon increased with increasing cytokinin concentration and decreased with the addition of auxin as either NAA or IAA to the optimal high cytokinin medium. Addition of NAA and IAA did not cause significant differences on cotyledon morphogenesis in some treatments but in media with a high cytokinin levels the presence of auxin did enhance root formation (data not showed). Therefore, greatest regeneration capacity was achieved with $2 \mathrm{mg} \cdot \mathrm{L}^{-1}$ BAP, $1 \mathrm{mg} \cdot \mathrm{L}^{-1} \mathrm{Kin}$ and $1 \mathrm{mg} \cdot \mathrm{L}^{-1}$ IAA resulting in the highest regeneration efficiency (52\%) and number of regenerated shoots per explant (1.89) although several other growth regulator combinations were not different at the $\mathrm{p}<0.05$ level. Inclusion of auxin enhanced root formation compared with the same treatment with similar levels of cytokinin (data not shown). Therefore this plant growth regulator regime was used in the selection media throughout genetic transformation experiments.

It has been shown that BAP is a requisite for optimal shoot regeneration in epicotyls, cotyledons, shoot tips, nodal and internodal stem segments of Citrus, while the effect of auxins seems to be marginal [21]-[25]. Our data demonstrate that in addition to BAP, inclusion of either Kin or IAA enhances shoot organogenesis from cotyledon explants.

\subsection{Kanamycin Sensitivity}

After the establishment of the optimal regeneration medium, we evaluated the response of cotyledons of Mexican lime cultured for 45 days in the presence of kanamycin at various concentrations $(0,15,20,30,40,50$ and 60 $\mathrm{mg} \cdot \mathrm{L}^{-1}$ ) to determine a suitable level for selection of transgenic plant cells within the non-transgenic explant tissue. Figure 3 indicated that Mexican lime cotyledons were extremely sensitive to kanamycin. Kanamycin at the relatively low concentration of $30 \mathrm{mg} \cdot \mathrm{L}^{-1}$ was detrimental to non-transformed organogenic potential without causing necrosis from antibiotic stress, such as visible browning of the cotyledon and reduced survival rate. In concentration of $40 \mathrm{mg} \cdot \mathrm{L}^{-1}$ kan or more, all explants turned brown and stopped growing. These results suggested that the concentration of $30 \mathrm{mg} \cdot \mathrm{L}^{-1}$ kanamycin would be effective for selection of transformants throughout transformation experiments.

\subsection{Optimization of Transformation Conditions for T-DNA Delivery into Cotyledons of Mexican Lime}

To determine optimal conditions for genetic transformation using cotyledons as explants, four studies were performed to establish optimal conditions for T-DNA delivery into tissue by Agrobacterium-mediated transformation (variables were vacuum infiltration and/or dipping, Agrobacterium concentration, co-cultivation period, and concentration of acetosyringone in co-cultivation medium). DsRed gene expression was used to monitor early transformation events.

The first experiment compared the vacuum infiltration and/or standard dipping (Table 1). DsRed expression increased with infiltration time up to 10 minutes, but longer infiltration hindered bacterial elimination and increased Agrobacterium overgrowth, resulting in reduced explants survival. Therefore, 10 minutes of vacuum infiltration was used in subsequent experiments. It has been reported that vacuum infiltration during Agrobacterium incubation period enhanced transformation efficiency in several species [9] [26]-[29] by improving pene- 

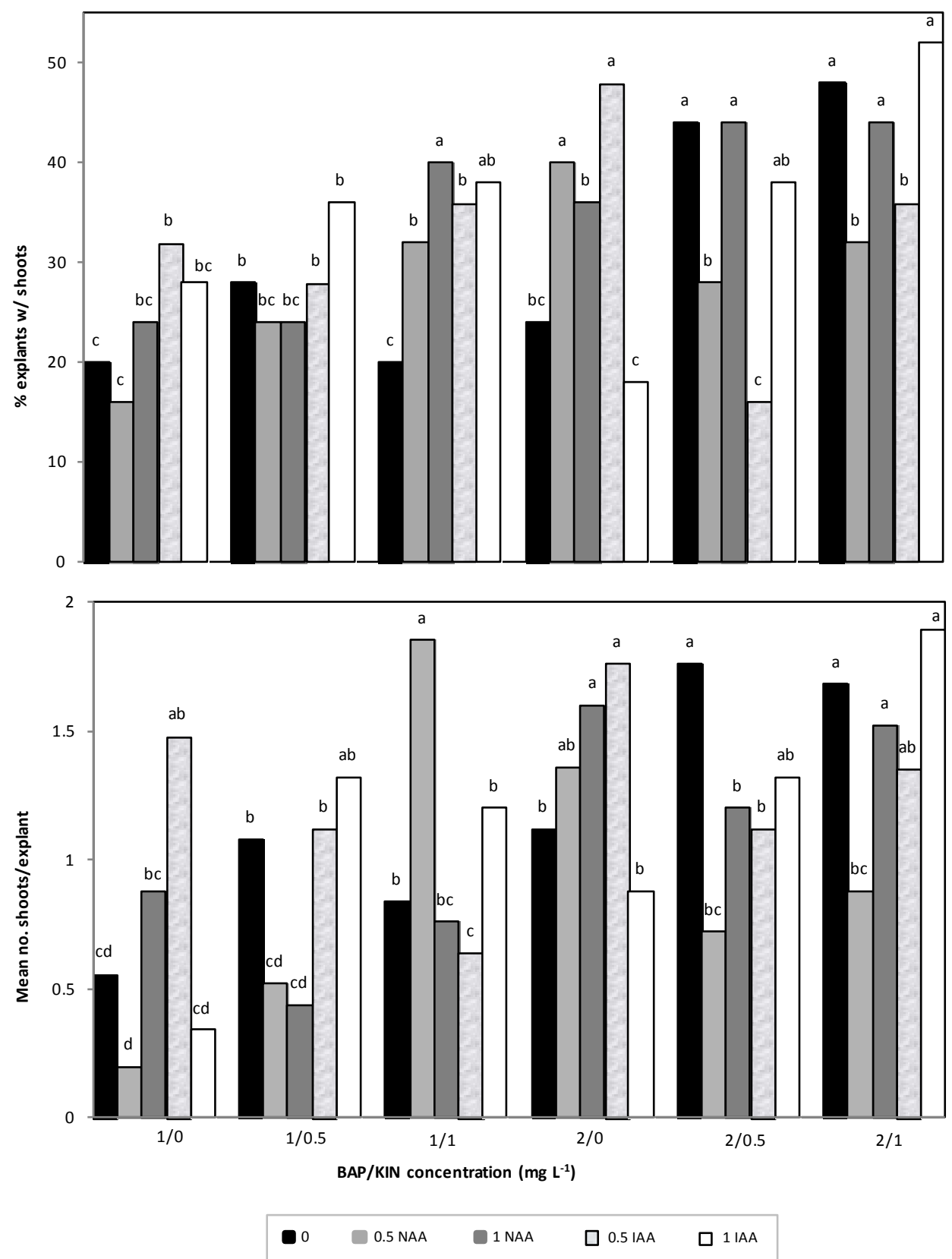

Figure 2. Organogenic response of cotyledon explants from Mexican lime to different concentrations and combinations of 6-benzyladenine (BAP), 6 -furfurylaminopurine (Kin), $\alpha$-naphthaleneacetic acid (NAA) and indole-3-acetic acid (IAA) in the shoot induction medium. Data are from two independent experiments. Means followed by the same letter do not differ significantly by Tukey HSD test $(\mathrm{p} \leq 0.05)$.

tration of Agrobacterium into the explants.

Transient expression was enhanced at bacterial density higher than $\mathrm{OD}_{600}$ of 0.25 (Table 1) but $\mathrm{OD}_{600}>1.0$ increased Agrobacterium overgrowth. Consequently, OD between 0.50 and 0.75 were chosen for subsequent transformation experiments.

Increase in co-culture period resulted in an increased rate of DsRed expression. Co-culture for 3 or 4 days resulted in the highest proportion of explants expressing DsRed (Table 1), in spite of 4 days resulted in Agrobacterium overgrowth on the explant surface and a subsequent decrease in the explants survival. Therefore, we used a 3 day co-cultivation for subsequent experiments. 


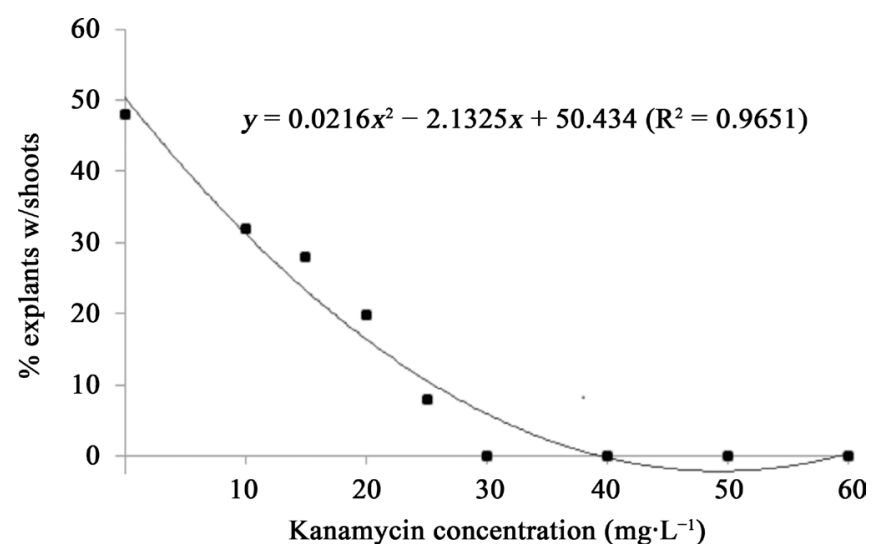

Figure 3. Shoot regeneration from cotyledon explants of Mexican lime as affected by different concentrations of kanamycin after 45 days in culture.

Table 1. DsRed transient expression assay measuring the effect of four parameters (and treatments) in Agrobacterium-mediated transient transformation of Mexican lime using embryo cotyledons: 1) Agro infiltration methods (use of vacuum chamber during Agrobacterium inoculation and/or dipping); 2) density of bacterial culture (0.25, $0.50,0.75$ and 1.0 $\left.\mathrm{OD}_{600}\right)$; 3) duration of co-cultivation period ( $0,1,2,3$ and 4 days); and 4) concentration of transformation enhancer (acetosyringone $0,50,100$ and $150 \mu \mathrm{M}$ ). Twenty five explants were analyzed by fluorescence stereoscopy (Olympus BX3) and the red explants were counted in each experiment. Values are the mean of three replicates \pm SE. Data are from two independent experiments. Means followed by the same letter within a column do not differ significantly by Tukey HSD test ( $\leq \leq 0.05)$.

\begin{tabular}{|c|c|c|c|c|}
\hline Parameters & & Explants tested & Reps & DsRed expressing explants ( $\mathrm{t}=10$ dac $)$ \\
\hline \multirow{4}{*}{ Agro infiltration methods } & Dipping 10 min & 25 & 3 & $5 \pm 3^{c}$ \\
\hline & Vacuum 5 min & 25 & 3 & $8 \pm 1^{\mathrm{bc}}$ \\
\hline & Vacuum 10 min & 25 & 3 & $17 \pm 2^{\mathrm{a}}$ \\
\hline & Vacuum 15 min & 25 & 3 & $11 \pm 4^{\mathrm{ab}}$ \\
\hline \multirow{4}{*}{ Density of bacterial culture $\left(\mathrm{OD}_{600}\right)$} & 0.25 & 25 & 3 & $8 \pm 3^{b}$ \\
\hline & 0.50 & 25 & 3 & $16 \pm 2^{\mathrm{a}}$ \\
\hline & 0.75 & 25 & 3 & $15 \pm 1^{\mathrm{a}}$ \\
\hline & 1.0 & 25 & 3 & $17 \pm 2^{\mathrm{a}}$ \\
\hline \multirow{4}{*}{ Duration of co-cultivation period (days) } & 1 & 25 & 3 & $5 \pm 2^{c}$ \\
\hline & 2 & 25 & 3 & $11 \pm 1^{\mathrm{b}}$ \\
\hline & 3 & 25 & 3 & $18 \pm 2^{\mathrm{a}}$ \\
\hline & 4 & 25 & 3 & $17 \pm 3^{\mathrm{a}}$ \\
\hline \multirow{4}{*}{ Transformation enhancer/acetosyringone $(\mu \mathrm{M})$} & 0 & 25 & 3 & $12 \pm 2^{\mathrm{b}}$ \\
\hline & 50 & 25 & 3 & $14 \pm 2^{\mathrm{b}}$ \\
\hline & 100 & 25 & 3 & $22 \pm 1^{\mathrm{a}}$ \\
\hline & 150 & 25 & 3 & $21 \pm 3^{\mathrm{a}}$ \\
\hline
\end{tabular}

Inclusion of acetosyringone at $100-150 \mu \mathrm{M}$ in the co-culture medium resulted in the greatest proportion of explants displaying transient DsRed expression. Acetosyringone at $150 \mu \mathrm{M}$ did not increase expression compared to $100 \mu \mathrm{M}$, therefore acetosyringone was used at $100 \mu \mathrm{M}$ in all subsequent experiments. The use of acetosyringone (AS) during co-culture increases Agrobacterium-mediated transformation frequencies has previously been seen in several Citrus genotypes, such as, sweet orange [30] [31], "Carrizo" citrange [32], and Rio Red grapefruit [33]. AS is a phenolic compound naturally produced during wounding of plant cells that induces the transcription of the virulence genes of Agrobacterium [34].

From these experiments we concluded that Agrobacterium-mediated transformation using cotyledon of Citrus was near optimal with the following protocol: cotyledons were vacuum infiltrated in inoculation suspension at $\mathrm{OD}_{600}$ of $0.5-0.75$ for $10 \mathrm{~min}$ followed by "resting" in the inoculum suspension for additional $10 \mathrm{~min}$, blotting 
on filter paper, and co-culture in the dark for 3 days with supplementation of $100 \mu \mathrm{M}$ of acetosyringone. Therefore, these optimized conditions of T-DNA delivery were evaluated on stable transformation efficiency. Figure 4 shows transient and stable DsRed transformation in Mexican lime, confirming the transgene integration using the optimized cotyledon transformation protocol.

\subsection{Molecular Analysis of Transgenic Plants}

PCR verified the stable transformation of Mexican lime (Table 2). Twenty-nine PCR positive shoots were recovered following transformation from 254 inoculated epicotyls (11.4\% of transformation efficiency), compared to 41 PCR positive shoots from 102 inoculated cotyledons ( $40.2 \%$ of transformation efficiency). Only $37.9 \%$ of PCR positive plantlets from epicotyls were rooted and successfully acclimated under greenhouse conditions, one third those obtained using the cotyledon transformation protocol where $92.6 \%$ of transgenic shoots were successfully established. This may largely be due to the shorter length of shoots obtained from epicotyl explants (Figure 5(A), Figure 5(B)), compared to longer shoots obtained from cotyledons (Figure 5(B), Figure 5(C)). The root systems produced from cotyledon-derived transgenic shoots (Figure 5(D)) were more vigorous compared to those derived from epicotyls (Figure 5(E)).

The results from Southern blot analysis done at 120 days after shoot establishment in the greenhouse, shows strong transgene amplification and hybridization in cotyledon-derived transgenic plants (Figure 5(F)), consistent with stable transformation.

It is important to note that in this study, putative transgenic shoots were directly induced from cotyledons without the intervening step of seed germination which does not require weeks of preparation and staging of materials necessary when using epicotyls explants. The transgenic shoots resulting from cotyledon transformation were longer and had more vigorous root systems than those from epicotyl transformation, further reducing the time from initiating the transformation protocol to successfully establishing rooted plants ex vitro. The shoots produced per explants, transformation frequency, and transgenic plant establishment per explant were significantly improved using cotyledon transformation compared with epicotyl transformation. The epicotyl ex-

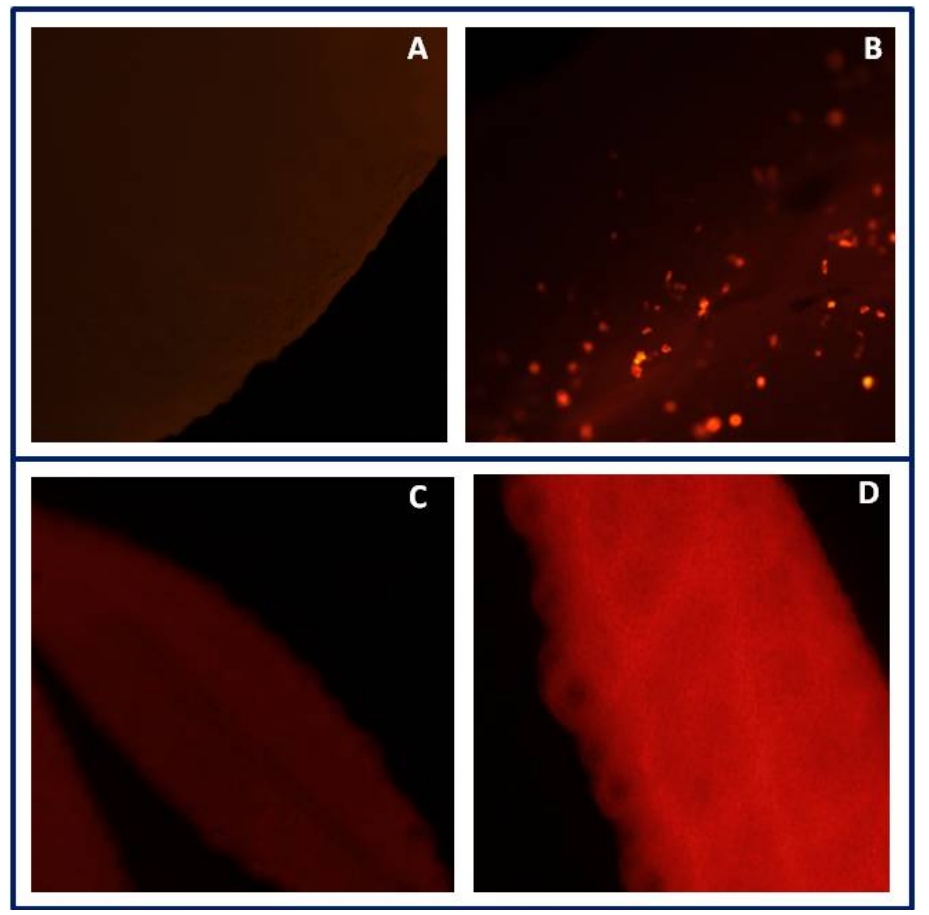

Figure 4. Transient and stable expression of DsRed fluorescent marker gene in Mexican lime in the embryo cotyledon and shoots under Olympus BX3 fluorescent microscope at 10× magnification using DsRed-specific filters. ((A)-(B)) In situ detection of DsRed expression in Mexican lime cotyledon co-cultivated with pCTAGDV-KCN3 for 10 days. (A) Non-transgenic cotyledon; (B) Cotyledon transgenic with optimized protocol. ((B)-(C)) Regenerating plant leaf with red fluorescence. (C) Non-transgenic plant; (D) transgenic plant line \#9. 
Table 2. Regeneration frequency, frequency of transgenic plant-recovery, and stable transformation efficiency of Mexican lime using epicotyls and embryo cotyledons explants.

\begin{tabular}{|c|c|c|c|c|c|}
\hline $\begin{array}{l}\text { Source of } \\
\text { Explants }\end{array}$ & $\begin{array}{c}\text { No. of } \\
\text { explants } \\
\text { inoculated }\end{array}$ & $\begin{array}{c}\text { No. of regenerated } \\
\text { shoots (Frequency of } \\
\text { shoot regeneration \%) }\end{array}$ & No. of $\mathrm{PCR}^{+}$shoots & $\begin{array}{l}\text { No. of rooted } \mathrm{PCR}^{+} \text {plantlets } \\
\text { (Frequency of transgenic } \\
\text { plant-recovery \%) }\end{array}$ & $\begin{array}{l}\text { Transformation } \\
\text { efficiency }(\%)^{\mathbf{x}}\end{array}$ \\
\hline Epicotyl & 254 & $36(14.1)$ & 29 & $11(37.9)$ & 11.4 \\
\hline Cotyledon & 102 & $57(55.8)$ & 41 & 38 (92.6) & 40.2 \\
\hline
\end{tabular}

${ }^{\mathrm{z}}$ Frequency of shoot regeneration was calculated as number of regenerated shoots divided by the number of explants inoculated;

${ }^{\mathrm{y}}$ Frequency of transgenic plant-recovery was calculated as number of rooted PCR+ plantlets transfer to the soil by the number of PCR ${ }^{+}$shoots;

${ }^{\mathrm{x}}$ Transformation efficiency was calculated as the number of $\mathrm{PCR}^{+}$shoots divided by the number of explants inoculated in Agrobacterium co-cultivation media.

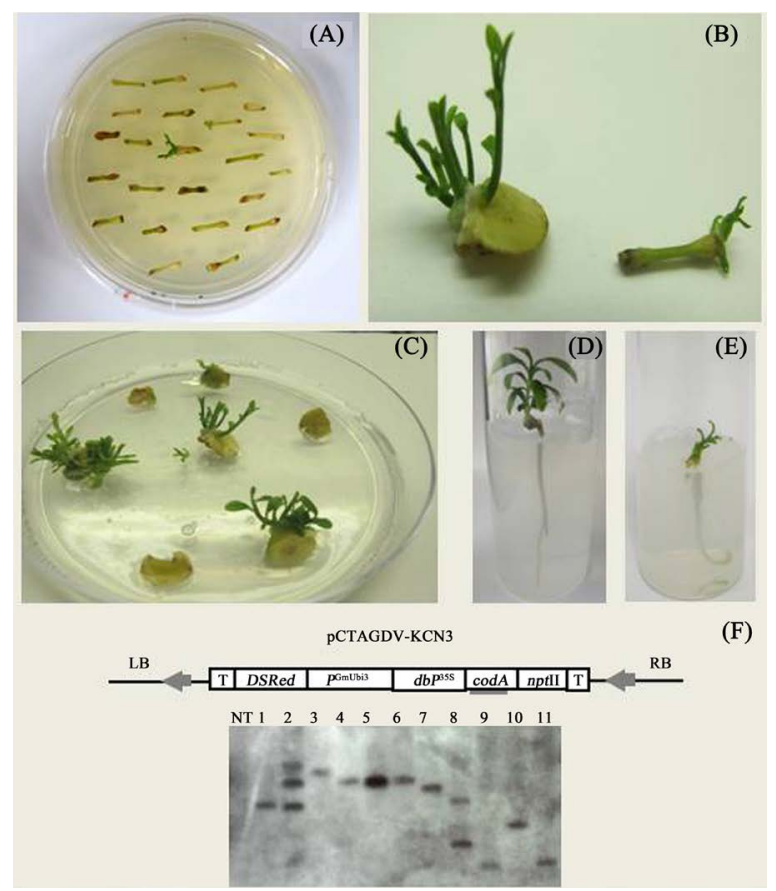

Figure 5. In vitro morphogenesis and Agrobacterium tumefaciens-mediated transformation of Mexican lime from epicotyls and cotyledon explants. (A). Adventitious bud formation on epicotyl explants after 6 weeks of culture on regeneration/selection MS medium containing $1 \mathrm{mg} \cdot \mathrm{L}^{-1} \mathrm{BAP}, 250 \mathrm{mg} \cdot \mathrm{L}^{-1}$ timentin, $250 \mathrm{mg} \cdot \mathrm{L}^{-1}$ cefotaxime, and $100 \mathrm{mg} \cdot \mathrm{L}^{-1} \mathrm{kanamycin}$; (B) Comparison side by side of adventitious bud on cotyledon and epicotyl explants after 6 weeks of culture on regeneration/selection medium; (C). Adventitious bud formation on cut edge of a cotyledon explant after 6 weeks of culture on regeneration/selection MS medium containing $2 \mathrm{mg} \cdot \mathrm{L}^{-1} \mathrm{BAP}, 1 \mathrm{mg} \cdot \mathrm{L}^{-1} \mathrm{Kin}, 1 \mathrm{mg} \cdot \mathrm{L}^{-1} \mathrm{IAA}, 250 \mathrm{mg} \cdot \mathrm{L}^{-1}$ timentin, $250 \mathrm{mg} \cdot \mathrm{L}^{-1}$ cefotaxime, and $30 \mathrm{mg} \cdot \mathrm{L}^{-1} \mathrm{ka}-$ namycin; (D). Rooted shoots from cotyledon after 21 days in MS medium containing NAA at $0.5 \mathrm{mg} \cdot \mathrm{L}^{-1}$; (E) Rooted shoots from epicotyl after 30 days in MS medium containing NAA at $0.5 \mathrm{mg} \cdot \mathrm{L}^{-1}$; (F) Schematic representation of the Agrobacterium binary vector T-DNA carrying the codA gene, and Southern Blot analysis of non-transgenic and transgenic Mexican lime codA lines derived from cotyledon transformation experiments. Total plant genomic DNA was digested with EcoRI and hybridized with a ${ }^{32}$ P-labeled codA probe (gray bar). Samples are listed as above. NT, negative control (non-transgenic Citrus plant) that has been regenerated from cotyledon segments; Lanes \#1 - 11 are codA transgenic lines.

plants transformation and establishment efficiencies generated in this study were similar to those previously reported for Mexican lime using a slightly different protocol [16] [17]. It must be noted that only two cotyledon explants are generated from each seed while as many as ten epicotyls explants are produced from each seed. However, production of epicotyl explants results in the loss of some seedlings to contamination and frequent discarding of some seedlings when initial staging does not correctly anticipate need for explants.

\section{Conclusion}

In conclusion, it has been demonstrated that cotyledons from Mexican lime are easily transgenic using A. tume- 
faciens. The use of cotyledon explants may be widely applicable for genetic transformation of Citrus. Transforming cotyledons directly rather than seedlings or juvenile plants is technically simpler, less time-consuming, and at least in Mexican lime produces transgenic plants at a greater efficiency than the standard Citrus transformation protocols. In addition, this shoot regeneration system based on cotyledons may facilitate the use of particle-bombardment technology for transformation of Citrus species that are difficult to transform via Agrobacterium. During the course of this project, we utilized the pCTAGDV-KCN3 vector for Mexican lime transformation [18]. This vector was designed to provide a genomic landing pad or founder line for Recombinase Mediated Exchange Cassette (RMCE) genome targeting. The system is designed specifically for stacking multiple transgenes in a site-specific and sequential manner and also removes unneeded selectable markers when completed [35]. Analysis of the RMCE targeted integration protocol is currently being investigated.

\section{Acknowledgements}

This research was financially supported by the California Citrus Research Board under project \# 5200-140A. This research was also supported by USDA Agricultural Research Service CRIS projects 5325-21000-018, 5325-21000-020, 6618-21000-014-00 and by the Biotechnology Risk Assessment Program competitive grant number 2010-33522-21773 from the USDA-National Institute of Food and Agriculture. Mention of trade names or commercial products is solely for the purpose of providing specific information and does not imply recommendation or endorsement by the US Department of Agriculture. USDA is an equal opportunity provider and employer.

\section{References}

[1] Cardoso S.C., Barbosa-Mendes, J.M., Boscariol-Camargo, R.L., Christiano, R.S.C., Filho, A.B., Vieira, M.L.C., Mendes, B.M.J. and Mourão Filho, F.A.A. (2010) Transgenic Sweet Orange (Citrus sinensis L. Osbeck) Expressing the Attacin A Gene for Resistance to Xanthomonas citri subsp. citri. Plant Molecular Biology Reports, 28, $185-192$. http://dx.doi.org/10.1007/s11105-009-0141-0

[2] Orbovic, V., Soria, P., Moore, G.A. and Grosser, J.W. (2011) The Use of Citrus Tristeza Virus (CTV) Containing a Green Fluorescent Protein Gene as a Tool to Evaluate Resistance/Tolerance of Transgenic Citrus Plants. Crop Protection, 30, 572-576. http://dx.doi.org/10.1016/j.cropro.2011.01.001

[3] He, Y., Chen, S., Peng, A., Zou, X., Xu, L., Lei, T., Liu, X. and Yao, L. (2011) Production and Evaluation of Transgenic Sweet Orange (Citrus sinensis Osbeck) Containing Bivalent Antibacterial Peptide Genes (Shiva A and Cecropin B) via a Novel Agrobacterium-Mediated Transformation of Mature Axillary Buds. Scientia Horticulturae, 18, 99-107. http://dx.doi.org/10.1016/j.scienta.2011.01.002

[4] Ali, S., Mannan A., Oirdi M.E., Waheed A. and Mirza B. (2012) Agrobacterium-Mediated Transformation of Rough Lemon (Citrus jambhiri Lush) with Yeast HAL2 Gene. BMC Research Notes, 5, 285. http://dx.doi.org/10.1186/1756-0500-5-285

[5] Bunnag S. and Tangpong, D. (2012) Genetic Transformation of Citrus sinensis L. with an Antisense ACC Oxidase Gene. American Journal of Plant Sciences, 3, 1336-1340. http://dx.doi.org/10.4236/ajps.2012.39161

[6] Dutt, M. and Grosser, J.W. (2010) An Embryogenic Suspension Cell Culture System for Agrobacterium-Mediated Transformation of Citrus. Plant Cell Reports, 29, 1251-1260. http://dx.doi.org/10.1007/s00299-010-0910-0

[7] Guo, W., Duan, Y., Olivares-Fuster, O., Wu, Z., Arias, C.R., Burns, J.K. and Grosser, J.W. (2005) Protoplast Transformation and Regeneration of Transgenic Valencia Sweet Orange Plants Containing a Juice Quality-Related Pectin Methylesterase Gene. Plant Cell Reports, 24, 482-486. http://dx.doi.org/10.1007/s00299-005-0952-x

[8] Costa, M.G.C., Otoni, W.C. and Moore, G.A. (2002) An Evaluation of Factors Affecting the Efficiency of Agrobacterium-Mediated Transformation of Citrus paradisi (Macf.) and the Production of Transgenic Plants Containing Carotenoid Biosynthetic Genes. Plant Cell Reports, 21, 365-373. http://dx.doi.org/10.1007/s00299-002-0533-1

[9] De Oliveira, M.L.P., Febres, V.J., Costa, M.G.C., Moore, G.A. and Otoni, W.C. (2009) High-Efficiency Agrobacterium-Mediated Transformation of Citrus via Sonication and Vacuum Infiltration. Plant Cell Reports, 28, 387-395. http://dx.doi.org/10.1007/s00299-008-0646-2

[10] Favero, P., Mourão Filho, F.A.A., Stipp, L.C.L. and Mendes, B.M.J. (2012) Genetic Transformation of Three Sweet Orange Cultivars from Explants of Adult Plants. Acta Physiologiae Plantarum, 34, 471-477. http://dx.doi.org/10.1007/s11738-011-0843-4

[11] Marutani-Hert, M., Bowman, K.D., McCollum, G.T., Mirkov, E., Evens, T.J. and Niedz, R.P. (2012) A Dark Incubation Period Is Important for Agrobacterium-Mediated Transformation of Mature Internode Explants of Sweet Orange, 
Grapefruit, Citron, and a Citrange Rootstock. PLoS ONE, 7, e47426. http://dx.doi.org/10.1371/journal.pone.0047426

[12] Chern, A., Hosskawa, Z., Cherubini, C. and Cline, M. (1993) Effects of Node Position on Lateral Bud out Growth in the Decapitation Shoot of Ipomoea nil. Ohio Journal of Sciences, 93, 11-13.

[13] Litz, R.E., Raharjo, S., Efendi, D., Pliego-Alfaro, F. and Barcelo-Munoz, A. (2005) Persea americana Avocado. In: Litz, R., Ed., Biotechnology of Fruit and Nut Crops, Cromwell Press, Trowbridge, 331-335. http://dx.doi.org/10.1079/9780851996622.0326

[14] Barcelo-Munoz, A., Encina, C.L., Simon-Perez, E. and Pliego-Alfaro, F. (1999) Micropropagation of Adult Avocado. Plant Cell Tissue and Organ Culture, 58, 11-17. http://dx.doi.org/10.1023/A:1006305716426

[15] Birch, R.G. (1997) Plant Transformation: Problems and Strategies for Practical Applications. Annual Reviews of Plant Physiology and Plant Molecular Biology, 48, 297-326. http://dx.doi.org/10.1146/annurev.arplant.48.1.297

[16] Dutt, M. and Grosser, J.W. (2009) Evaluation of Parameters Affecting Agrobacterium-Mediated Transformation of Citrus. Plant Cell Tissue and Organ Culture, 98, 331-340. http://dx.doi.org/10.1007/s11240-009-9567-1

[17] Dutt, M., Vasconcellos, M. and Grosser, J.W. (2011) Effects of Antioxidants on Agrobacterium-Mediated Transformation and Accelerated Production of Transgenic Plants of Mexican Lime (Citrus aurantifolia Swingle). Plant Cell Reports, 107, 79-89. http://dx.doi.org/10.1007/s11240-011-9959-x

[18] De Oliveira, M.L.P., Stover, E. and Thomson, J.G. (2015) The codA Gene as a Negative Selection Marker in Citrus. SpringerPlus, 4, 264. http://dx.doi.org/10.1186/s40064-015-1047-y

[19] Štorchová, H., Hrdlièková, R., Chrtek Jr., J., Tetera, M., Fritze, D. and Fehrer, J. (2000) An Improved Method of DNA Isolation from Plants Collected in the Field and Conserved in Saturated NaCl/CTAB Solution. Taxon, 49, 79-84. http://dx.doi.org/10.2307/1223934

[20] Donmez, D., Simsek, O., Izgu, T., Aka, K.Y. and Yesim, Y.M. (2013) Genetic Transformation in Citrus. The Scientific World Journal, 2013, Article ID: 491207. http://dx.doi.org/10.1155/2013/491207

[21] Bordón, Y., Guardiola, J.L. and García-Luis, A. (2000) Genotype Affects the Morphogenic Response in Vitro of Epicotyl Segments of Citrus Rootstocks. Annals of Botany, 86, 159-166. http://dx.doi.org/10.1006/anbo.2000.1177

[22] Paudyal, K.P. and Haq, N. (2000) In Vitro Propagation of Pummel (Citrus grandis L. Osbeck). In Vitro Cell and Developmental Biology, 36, 511-516. http://dx.doi.org/10.1007/s11627-000-0091-6

[23] Moreira-Dias, J.M., Molina, R.V., Bordon, Y., Guardiola, J.L. and Garcia-Luis, A. (2000) Direct and Indirect Shoot Organogenic Pathways in Epicotyl Cuttings of Troyer citrange Differ in Hormone Requirements and in Their Response to Light. Annals of Botany, 85,103-110. http://dx.doi.org/10.1006/anbo.2000.1001

[24] Cervera, M., Navarro, A., Navarro, L. and Peña, L. (2008) Production of Transgenic Adult Plants from Clementine Mandarin by Enhancing Cell Competence for Transformation and Regeneration. Tree Physiology, 28, 55-66. http://dx.doi.org/10.1093/treephys/28.1.55

[25] Rodríguez, A., Cervera, M., Peris, J.E. and Peña, L. (2008) The Same Treatment for Transgenic Shoot Regeneration Elicits Opposite Effect in Mature Explants from Two Closely Related Sweet Orange (Citrus sinensis (L.) Osb. Genotypes. Plant Cell Tissue and Organ Culture, 93, 97-106. http://dx.doi.org/10.1007/s11240-008-9347-3

[26] Amoah, B.K., Wu, H., Sparks, C. and Jones, H.D. (2001) Factors Influencing Agrobacterium-Mediated Transient Expression of uidA in Wheat Inflorescence Tissue. Journal of Experimental Botany, 52, 1135-1142. http://dx.doi.org/10.1093/jexbot/52.358.1135

[27] Charity, J.A., Holland, L., Donaldson, S.S., Grace, L. and Walter, C. (2002) Agrobacterium-Mediated Transformation of Pinus radiata Organogenic Tissue Using Vacuum-Infiltration. Plant Cell Tissue Organ Culture, 70, 51-60. http://dx.doi.org/10.1023/A:1016009309176

[28] Acereto-Escoffié, P.O.M., Chi-Manzanero, B.H., Echeverría-Echeverría, S., Grijalva, R., Kay, A.J., González-Estrada, T., Castaño, E. and Rodrígues-Zapata, L.C. (2005) Agrobacterium-Mediated Transformation of Musa acuminata cv. “Grand Nain” Scalps by Vacuum Infiltration. Scientia Horticulturae, 105, 359-371. http://dx.doi.org/10.1016/j.scienta.2005.01.028

[29] Canche-Moo, R.L.R., Ku-Gonzalez, A., Burgeff, C., Loyola-Vargas, V.M., Rodríguez-Zapata, L.C. and Castaño, E. (2006) Genetic Transformation of Coffea canephora by Vacuum Infiltration. Plant Cell Tissue and Organ Culture, 84, 373-377. http://dx.doi.org/10.1007/s11240-005-9036-4

[30] Bond, J.E. and Roose, M.L. (1998) Agrobacterium-Mediated Transformation of the Commercially Important Citrus Cultivar Washington Navel Orange. Plant Cell Reports, 18, 229-234. http://dx.doi.org/10.1007/s002990050562

[31] Mendes, B.M.J., Boscariol, R.L., Mourão Filho, F.A.A. and De Almeida, W.A.B. (2002) Agrobacterium-Mediated Genetic Transformation of "Hamlin" Sweet Orange. Pesquisa Agropecuaria Brasileira, 37, 955-961. http://dx.doi.org/10.1590/S0100-204X2002000700009

[32] Cervera, M., Pina, J.A., Juárez, J., Navarro, L. and Peña, L. (1998) Agrobacterium-Mediated Transformation of Ci- 
trange: Factors Affecting Transformation and Regeneration. Plant Cell Reports, 18, 271-278. http://dx.doi.org/10.1007/s002990050570

[33] Yang, Z.N., Ingelbrecht, I.L., Louzada, E., Skaria, M. and Mirkov, T.E. (2000) Agrobacterium-Mediated Transformation of the Commercially Important Grapefruit Cultivar Rio Red (Citrus paradisi Macf.). Plant Cell Reports, 19, 12031211. http://dx.doi.org/10.1007/s002990000257

[34] De la Riva, G.A., González-Cabrera, J., Vázquez-Padrón, R. and Ayra-Pardo, C. (1998) Agrobacterium tumefaciens: A Natural Tool for Plant Transformation. Electronic Journal of Biotechnology, 1, 24-25.

[35] Wang, Y., Yau, Y.-Y., Perkins-Balding, D. and Thomson, J. (2011) Recombinase Technology: Applications and Possibilities. Plant Cell Reports, 30, 267-285. http://dx.doi.org/10.1007/s00299-010-0938-1 